\title{
Establishing basic requirements for textile and garment mass production units in the Tanzanian context
}

DOI:

10.1108/RJTA-11-2019-0054

\section{Document Version}

Accepted author manuscript

Link to publication record in Manchester Research Explorer

\section{Citation for published version (APA):}

Taifa, I. W. R., \& Lushaju, G. G. (2020). Establishing basic requirements for textile and garment mass production units in the Tanzanian context. Research Journal of Textiles and Apparel, 24(4), 321-340.

https://doi.org/10.1108/RJTA-11-2019-0054

\section{Published in:}

Research Journal of Textiles and Apparel

\section{Citing this paper}

Please note that where the full-text provided on Manchester Research Explorer is the Author Accepted Manuscript or Proof version this may differ from the final Published version. If citing, it is advised that you check and use the publisher's definitive version.

\section{General rights}

Copyright and moral rights for the publications made accessible in the Research Explorer are retained by the authors and/or other copyright owners and it is a condition of accessing publications that users recognise and abide by the legal requirements associated with these rights.

\section{Takedown policy}

If you believe that this document breaches copyright please refer to the University of Manchester's Takedown Procedures [http://man.ac.uk/04Y6Bo] or contact uml.scholarlycommunications@manchester.ac.uk providing relevant details, so we can investigate your claim.

\section{OPEN ACCESS}


Establishing basic requirements for textile and garment mass production units in the Tanzanian context

\begin{tabular}{|r|l|}
\hline Journal: & Research Journal of Textile and Apparel \\
\hline Manuscript ID & RJTA-11-2019-0054.R3 \\
\hline Manuscript Type: & Original Manuscripts \\
\hline Keyword: & $\begin{array}{l}\text { Garment industry, Mass production, Tanzania, Toolkit, Small and } \\
\text { medium-sized enterprises, Basic requirements }\end{array}$ \\
\hline \multicolumn{2}{|l}{} \\
\hline
\end{tabular}

\section{SCHOLARONE \\ Manuscripts}




\title{
Establishing basic requirements for textile and garment mass production units in the Tanzanian context
}

\begin{abstract}
Purpose - Garment making by the Small and medium-sized enterprises (SMEs) has existed for a long enough time to make the sewing culture a mainstream phenomenon today. It is thus essential to evaluate existing producers, the required information and the key requirements for production. This should consequently forge the way forward. Hence, this study establishes guidelines for the basic requirements as a means of operating garment mass production units in consideration of the unique economic, legal and social environment in Tanzania.
\end{abstract}

Design/methodology/approach - The study deployed a qualitative approach - interview sessions, questionnaires and observation together with the document review approach. A qualitative approach captured in-depth views, ideas and concepts from participants.

Findings - The study established the requirements for scaling up SMEs into mass production. The requirements include significant investment, well-planned strategies and implementable industrialisation plan. The country also requires empowered workforces through the existing institutions, international collaborations with foreign investors, implementable policies, among others to excel in this sector.

Research limitations/implications - The identified information together with all factors are leading towards initiating textile-based industries. Thus, information resources concerning garment production in the Tanzanian context are suitable for both individuals and corporations intending to scale up their production.

Originality/value - It is probably among the first studies in Tanzania which explored the basic requirements for setting mass-production units for textile and apparel industries. The uniqueness relies on the involved participants from multi-perspective domains.

Keywords Garment industry, Mass production, Tanzania, Toolkit, Small and medium-sized enterprises, Basic requirements

Paper type Research paper 


\section{Introduction}

In Tanzania, the earliest large-scale textile factory started production activities in 1959. The owner was a Taiwanese businessman who got funding from local Asian investors (Jones, 1983; Coulson, 2016). Afterwards, Tanzania got her political independence in 1961 (Kinabo, 2004). This was when the second mill was installed (Coulson, 2016). A few years later witnessed "a sudden cluster of investments" in the textile industry (Rweyemamu, 1973). Since then, the country has put efforts to reinforce the textile industry as a means of utilising plentily available resources, including workforces and cotton. The success of such a strategy would have satisfied the local demand (Kinabo, 2004). Between 1960 and 1970s, the country met the local demand regarding garments (Gabagambi, 2013). Before the 1990s' reforms, Tanzania's textile and apparel (T\&A) sector was blossoming (Berry et al., 2007). Soon after the halt of government support, together with the full rigour of international competition, the sector over a short time declined. Since the early 2000 s, the government has "sold off" manufacturing plants to several private investors. Investors found inefficient and antiquated equipment bought in the early 2000s (Salm et al., 2011). Such a situation hindered the likely success from these companies, and the sector did not prosper both domestically and internationally. Some investors renovated the "cotton-to-clothing" sector. To date, many existing firms still face such a constraint. Undeniably, for the industries which replaced or upgraded their machinery and equipment, such equipment are third-hand or second-hand. Several machineries are also of old and obsolete technology. This hinders companies to compete in accomplishing mass production successfully: leaving the companies under high pressure and risks.

The garment industry constitutes several components. The components are brought together by logistics feats that enable the production of textile products, such as garments, through highly organised production systems. This being the nature of such an industry, it may present some challenges to determine the necessary requirements to establish such an industry successfully.

The garment industry in Tanzania is relatively constrained regarding the offered products and size. In such cases, the aim is to produce for exportation (USAID, 2014) because fundamentally the production was to export to the European Union (EU) (Gabagambi, 2013) and the United States of America (USA) (Salm et al., 2011). The USA market was a crucial target in benefiting trade preferences due to AGOA. The domestic market is much restricted to promotional garments (apparel) and caps. Notwithstanding the momentous potentials that were available in the mid-2000s, the sector has been unsuccessful in advancing its production. There 
are some Sub-Saharan African (SSA) countries, including Swaziland, Kenya and Lesotho, which have at least improved (Salm et al., 2011).

The failure of the domestic garment industry attracted international retailers and brands. By now, the domestic clothing market is heavily dominated by foreign products (Calabrese et al., 2017; Sun, 2018). There is a need for setting good policies and strategies in reducing the importation of garments. This is a big opportunity. The Ministry in charge, together with other key stakeholders within Tanzania and the private sector, should capitalise on such an opportunity. This might help the dominance of the domestic garment market. Nevertheless, the country under the revised 'Domestic Industrialisation Plan (DIP)' is now rising up by exporting globally, regionally and locally with preferential access to the USA (50\%), the United Kingdom (6\%), Kenya (10\%), South Africa (23\%), Uganda (8\%), and others (3\%) (ITC, 2016; TDU, 2018). All the required initiatives, with the ongoing practices, should spur mass production initiatives to meet huge demands as the Tanzania population increases daily.

Currently, there are few Tanzanian owned apparel mass production units for domestic apparel needs (TDU, 2018). Even for international export, they are few and far apart. TDU (2018) mentions that at a glance the established industries in Tanzania includes four factories in Dar es Salaam, Arusha (2), Morogoro (2), Shinyanga (1) and Mwanza (1). By 2002, the country had already established 50 industries. Of these, only 23 (46\%) were still operating by then (Kinabo, 2004). By 2018, there were 10 (20\%) industries operating (TDU, 2018). Such decline proves that the T\&A industry is in a critical situation. Despite the new DIP and the incredible potentials within Tanzania, still, the T\&A industries have not yet shown significant impacts on economic and industrial levels. Similarly, there is equivalently no collective information resource on apparel mass production in Tanzania. The cost of this information not being available, or any action being taken, is the lost job opportunities and revenues. This leads further to the loss incurred by all textile fabrics or raw materials not converted to garments. Instead, they are exported and resold to Tanzania as garments. It is thus apparent that there is a need for the identification and organisation of all the pertinent information surrounding the establishment of garment mass production (GMP) units to empower capable individuals to initiate such projects.

In order to solve the above-stated problem, we conducted a study mainly to establish a guideline for all the requirements to operate a GMP unit in consideration of the unique economic, legal and social environment in Tanzania. The specific research questions included: 
first, what essential information and potential partnerships are required for interested parties and small and medium-sized enterprises (SMEs) to establish and operate a GMP unit in Tanzania? Second, what are crucial benefits to be considered in establishing a GMP unit in Tanzania?

This research is grounded in the industrial training at some SMEs garment production facilities in Tanzania. Here, various intricacies were involved in the GMP processes. Notwithstanding the faced challenges, several benefits were also associated with working in the Tanzanian context. Thus, as a result of seeing a glimpse of the possibilities that can come from operating a GMP unit, it spurred researching this further. The study takes into consideration the industrial, economic and political atmosphere in Tanzania. This being the matter, it was seen as possibly an advantageous time to establish requirements. Such information should include the guidelines on starting a mass-production unit for the garment (apparel) by scaling up the available SMEs which cannot compete with foreign manufacturers.

The remaining parts of this paper are as follows. Section 2 describes the theoretical background of the T\&A sector in Tanzania, compares the T\&A sector in Tanzania in comparison to the few selected countries and summarises the related studies. Section 3 elaborates the applied methodology, including the sampling method, the participants' characterisation, data collection and the validity testing. Results analysis and discussion are in Section 4, while Section 5 gives the requirements or toolkit. Section 6 details the specific consideration for Tanzania, while Section 7 discusses the practical implications of this study. Finally, Section 8 summarises the conclusion, recommendations and possible future studies.

\section{Theoretical background}

\subsection{Overview}

In most developing countries, the $\mathrm{T} \& \mathrm{~A}$ industries contribute significantly to national economic growth (Bheda et al., 2003; Berry et al., 2007; Calabrese et al., 2017). The initial point for industrialisation in several countries was the textile industries (Fukunishi and Yamagata, 2013). There was an Industrial revolution (1770-1800) led by the UK textile industry mid-18th and mid-19th Century (Fukunishi and Yamagata, 2013; Bertola and Teunissen, 2018; Taifa et al., 2019). Mass production is traced back to the early 1900s (Duguay et al., 1997; Selladurai, 2004). During that time, there were three fundamental characteristics, namely mechanisation, interchangeable parts and division of labour (Duguay et al., 1997). Mass production was most typical when Henry Ford developed the modern production line for 
the automobile industry. Selladurai (2004) states that "continuous improvement methods" for production were the result of mass production processes. Duguay et al. (1997) state four major characteristics of mass production. (a) Economies of scale: the mass producers are principally related to cost reduction by increasing the production volume. Mass producers cogitate on trade-offs concerning the numerous performance criteria - time, quality and cost as a need. (b) Production improvement process relies on innovativeness. (c) There is a design or execution dichotomy; execution of the production tasks are achieved through managers' supervision. (d) It is easier to create a nearly "adversarial relationship" with the available suppliers. Here, the suppliers become opportunists, thus being carried on at “arm's length", and such become pitted against one another to achieve conceivable deals.

Tanzania has ten large factories (Mtunga, 2016; TDU, 2018) which can take advantage of mass production opportunities. However, the country has many SMEs manufacturing garments. These enterprises need to be reinforced to increase their capacities for scaling up mass production. There are trade preferences which can be utilised including AGOA, SADC (Southern African Development Community) (Morris and Staritz, 2014), East Africa Community (EAC) (Mtunga, 2016), EBA (Faber and Orbie, 2009) and Export Processing Zone Authority (EPZA) (Salm et al., 2011). This creates great opportunities, but without garment industries which can make mass-production, Kenya and Mauritius would continue to lead the market. Moreover, despite the presence of all these opportunities, Tanzania has probably not shown great competition concerning the AGOA's opportunities when compared to other African countries. Figure 1 depicts the statistics for AGOA exports between 2010 and 2015 (with the exclusion of the "Generalized System of Preferences - GSP") for the EAC. Kenya has profited much from AGOA compared to Tanzania.

\begin{tabular}{|c|c|c|c|c|c|c|c|c|}
\hline & & & & & & & & \\
\hline & 400,000 & & & & & & & \\
\hline & 300,000 & & & & & & & \\
\hline & 200,000 & & & & & & & \\
\hline & 100000 & & & & & & & \\
\hline & 0 & $-=0$ & & 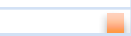 & & & $=$ & \\
\hline $\begin{array}{l}\text { United States } \\
\text { Dollar in thousands }\end{array}$ & 0 & Ethiopia & Kenya & $\begin{array}{l}\text { Madagas } \\
\text { car }\end{array}$ & Mauritius & Rwanda & Tanzania & Uganda \\
\hline & 2010 & 6,882 & 220,646 & 0 & 117,911 & 10 & 1,850 & 345 \\
\hline & 2011 & 10,879 & 288,331 & 0 & 155,982 & 17 & 5,131 & 787 \\
\hline & 2012 & 18,301 & 287,836 & 0 & 160,030 & 8 & 10,446 & 64 \\
\hline & 2013 & 31,714 & 336,601 & 0 & 188,260 & 9 & 10,360 & 56 \\
\hline & 2014 & 35,675 & 417,136 & 42 & 218,173 & 187 & 17,486 & 59 \\
\hline & 2015 & 40,780 & 427,437 & 39,831 & 206,906 & 435 & 28,166 & 144 \\
\hline
\end{tabular}

Figure 1. Statistics for AGOA exports between 2010 and 2015 (USAID, 2016). 
We furthermore evaluated Tanzania garment industry in comparison to other countries. For example, Nhung and Thuy (2018) highlighted the key statistics of textile industries in Vietnam as follows. The sector contributes highly to the national economy, creates over 16 million workforces, the private sector owns $84 \%$ of the industry, foreigners own $15 \%$, and the state-owned enterprises own 1\%. For Kenya, T\&A contributes $0.6 \%$ to the national GDP and accounts for $6 \%$ of the "manufacturing sector." By the 1990s, Kenya had 110 large scale garment manufacturers, and by 2004, there were 55 garment manufacturers. By 2016, Kenya had 22 large foreign-owned companies, eight ginneries, 170 medium and large companies, eight spinners, nine accessories manufacturers, 15 knitting and weaving companies, and more than 75,000 micro and small companies (Omolo, 2006; Equity Bank, 2016). Madagascar industry, by 2008, they had 118 firms, that is, 47 firms domestically owned while 71 firms owned by foreigners. Then, by 2011 , the share of exports was US (9.1\%), South Africa $(8.8 \%)$, EU-15 (75.3\%), among others and by December 2012, there were 64 plants and 55 firms of apparel manufacturers (Fukunishi and Ramiarison, 2012; Morris and Staritz, 2014).

For Pakistan, according to Fukunishi and Ramiarison (2012) and Morris and Staritz (2014), the total export through the textile industry is around $52 \%$. It creates $40 \%$ of the total manufacturing labour forces. The sector employs 3 million and 9 million directly and indirectly, respectively. The gross domestic products (GDP) is about $8.5 \%$ for the value-added of this sector, and the share for the market capitalisation is $8.3 \%$. For the Tanzania T\&A industry, the first and second large-scale textile factories were established in 1959 and 1961, respectively. In 1977, Tanzania had 23 mills, i.e. the public-owned were 15, and private investors owned eight mills. In the 1980s there were 50 factories, whereby by 2002 only 23 were in operation. The sector created 40,000 employment. In 2015, only 12 factories were active. By 2018, only ten factories were operating and employed 200,000 (Coulson, 2016; Mtunga, 2016; TDU, 2018). This shows a gap between Tanzania and other countries. Hence, this makes the argument of benchmarking from those countries and brings a need for scaling up the sector by establishing guidelines.

\subsection{Related studies}

There are studies concerning T\&A manufacturing in Tanzania. However, hardly any study explored intensively by involving manufacturers, SMEs, potential investors, the graduate university students (from textile programmes), and other pertinent organisations to establish a toolkit and basic requirements for scaling up their internal capacities. The scaling-up process is considered as taking advantages of the available trade preferences for Tanzania. 
Nevertheless, "starting a business is one thing and winning customers is another thing" (Nzumile and Taifa, 2019). Therefore, when scaling-up the T\&A industries, marketing principles and techniques should not be ignored. Mtunga (2016) looked into the general profile of cotton and the T\&A sector investment. Mtunga (2016) did not establish the basic requirements for enlarging the SMEs. USAID's (2014) study considered how to strengthen the value chain for the T\&A sector. Strengthening the value chain is essential. However, it is crucial to increase the internal capacities of SMEs to increase their productivity. Since Tanzania T\&A sector is not operating efficiently, Coulson (2016) investigated the reason for failures. Coulson (2016) associated liberalisation with the poor performance of the sector. Coulson (2016) did not study the possibilities of reviving up the sector, particularly on empowering the SMEs. Coulson (2016) recommended the necessity for the existing institutions that they epitomise the "economic interests of small farmers" for cotton and not "the cottonto-clothing." So far, there is equivalently no aggregated information resource on apparel mass production in Tanzania.

\section{Methodology}

\subsection{Deployed method}

This study began through general observation during the industrial training at some SMEs garment production facilities in Tanzania. As a result of seeing a glimpse of the possibilities that can come from operating a GMP unit, it thus drove researching this further. Amongst the deductive, abductive and inductive approaches, this research is more of inductive reasoning as the observations brought tentative questionnaires that assisted in producing the generalisation of the basic requirements for establishing mass production units. An inductive approach was considered because such an approach is pertinent for small samples which generate qualitative data and also relies on the activeness of the researchers' efforts. Thus, the study involved a qualitative approach, i.e. interview sessions, questionnaires, observation and a documentary review of the relevant reports and browsed relevant websites. The questionnaires and interview questions are in Figure 2. Meetings for collecting qualitative data took three months, whereby both questionnaires were physically provided to participants after having explained to them the research purposes and having obtained their consents. Also, the same processes were followed for the semi-structured interviews to the participants. Some information (Tables 3 and 4) were generated through a documentary review method. The interviews were analysed through 'content analysis' to obtain the explained vital information in Sections 5 and 6. For example, some details shown in Figure 12 were generated by the conducted interview sessions. For the 
questionnaires, Microsoft ${ }^{\circledR}$ Excel version 2016 analysed all the received questionnaires. Although the inductive reasoning (approach) assisted in establishing the basic requirements successfully, such an approach is challenged for generalising conclusions and any theory that comes from a small number of samples and observations.

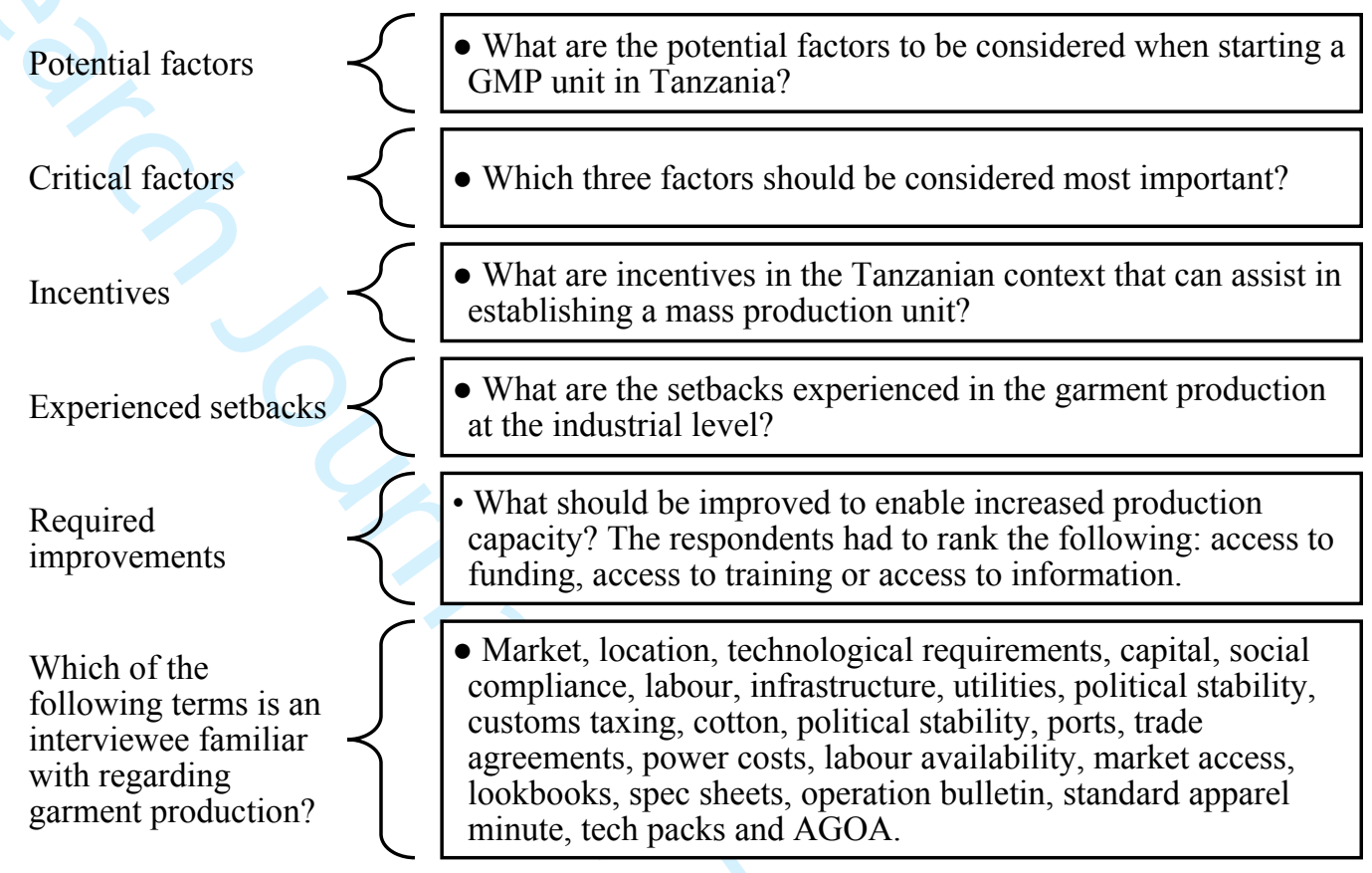

Figure 2. Considered questions for the questionnaires and interview sessions.

\subsection{Sampling method and the participants' characterisation}

Sampling technique determined the appropriate respondents (Taifa and Desai, 2016). We deployed deliberate sampling, i.e., the purposive, expert judgement or the non-probability sampling technique. The conducted interviews constituted specific perspectives of the garment industry in Tanzania. Table 1 depicts a summary of the consulted participants. Description of all participants consisted of groups of interviewees shown in Figure 3. Concerning the potential investors or entrepreneurs in garment production, information about their financial background, project handling and managerial or leadership and risk handling capability, as well as related experience in the T\&A sector, are required to be able to become potential entrepreneurs.

[Insert Table 1] 


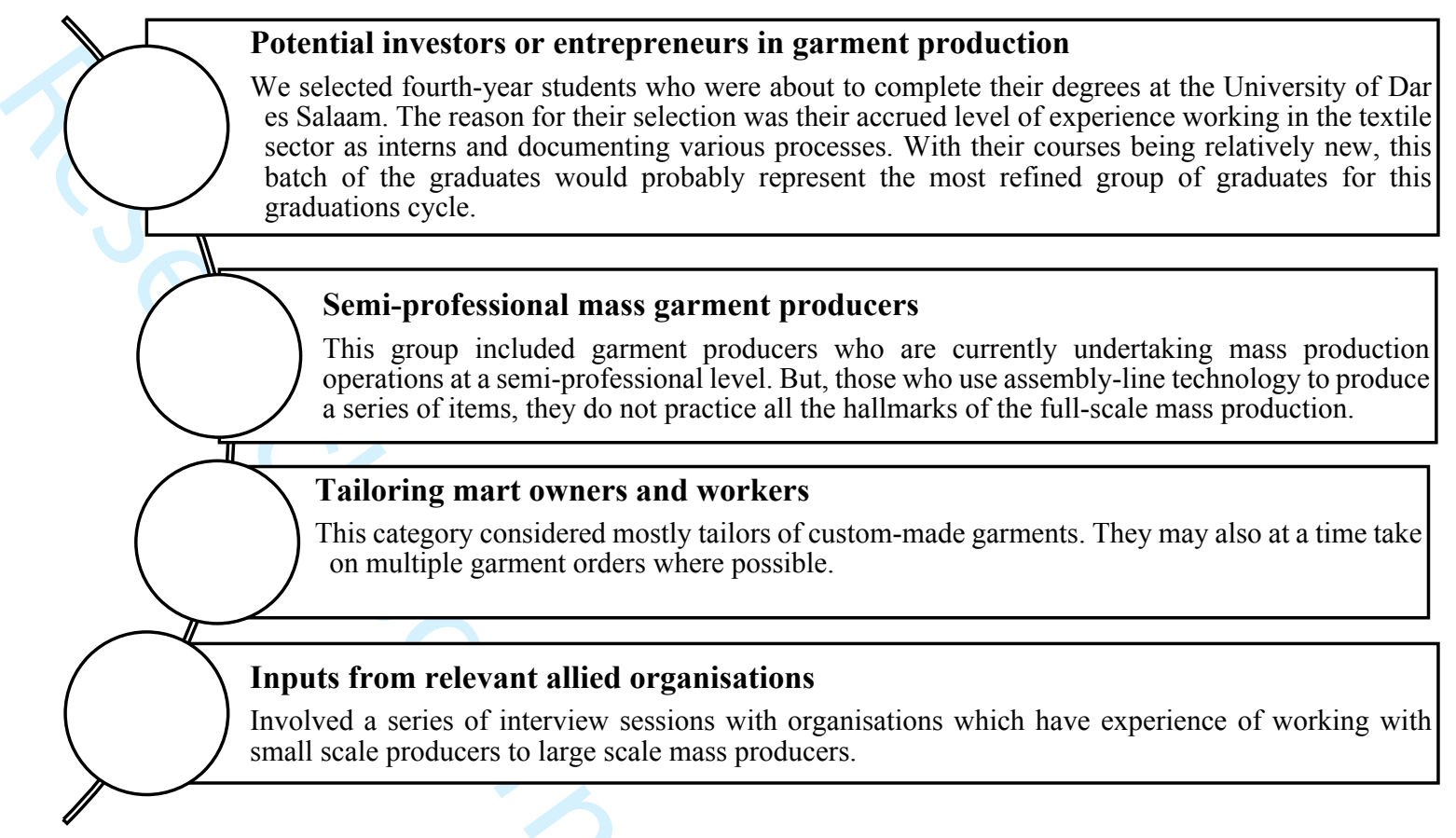

Figure 3. Participants' characterisation

\subsection{Data collection and validity testing}

One hundred sixteen questionnaires were distributed to different categories in Figure 3. The response rate was $62.1 \%$, i.e. 72 questionnaires ( 47 males, 25 females). The questionnaires' details can be tested for validity, reliability, readability, etc. For validity, the researchers can apply content validity, face validity, clean dataset, convergent validity, discriminant validity, predictive, factorial validity, hypothesis testing validity, known-group validity, etc. (Bolarinwa, 2015). For reliability, the techniques like Cronbach's Alpha $(\alpha)$ (internal consistency or homogeneity) (Taifa, 2016), principal components analysis, alternate-form reliability (or equivalence), test-retest reliability (or stability), among others can be deployed (Bolarinwa, 2015). Thus, this study deployed Cronbach's Alpha to test the internal consistency of the used questionnaires. The Cronbach's $\alpha$ value was 0.909 (excellent remark) indicating that the used questionnaires were with "high internal consistency" since $\alpha \geq 0.9$.

\section{Results analysis and discussion}

Figure 4 indicates that location, capital and technical requirements are the most prospective factors to establish a GMP unit. Another important finding was that political stability has a zero score for the similar reason of the producers being able to operate in the current political atmosphere of the country. The research found that garment manufacturers can cope with 
various changes in political situations. Tanzania is also not associated with political instability, particularly the insecurity, which can destabilise business operations. The research further explored the dominating factors whereby market, capital and labour featured (Figure 5). Since the T\&A industry is labour-intensive, the fact that access to qualified labourers is necessary should not be a surprise.

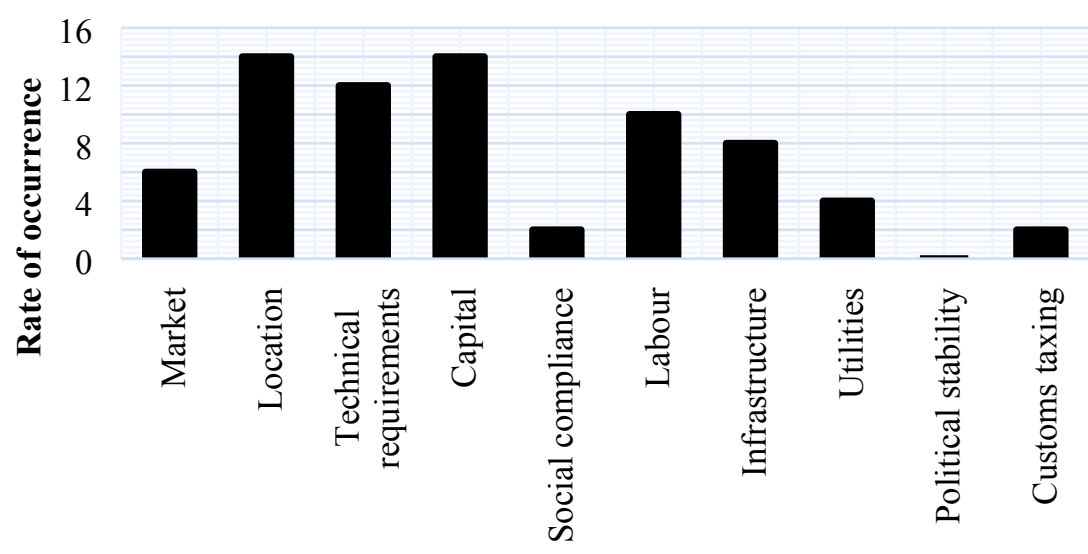

Factors for mass production in Tanzania

Figure 4. Potential factors for mass production in Tanzania.

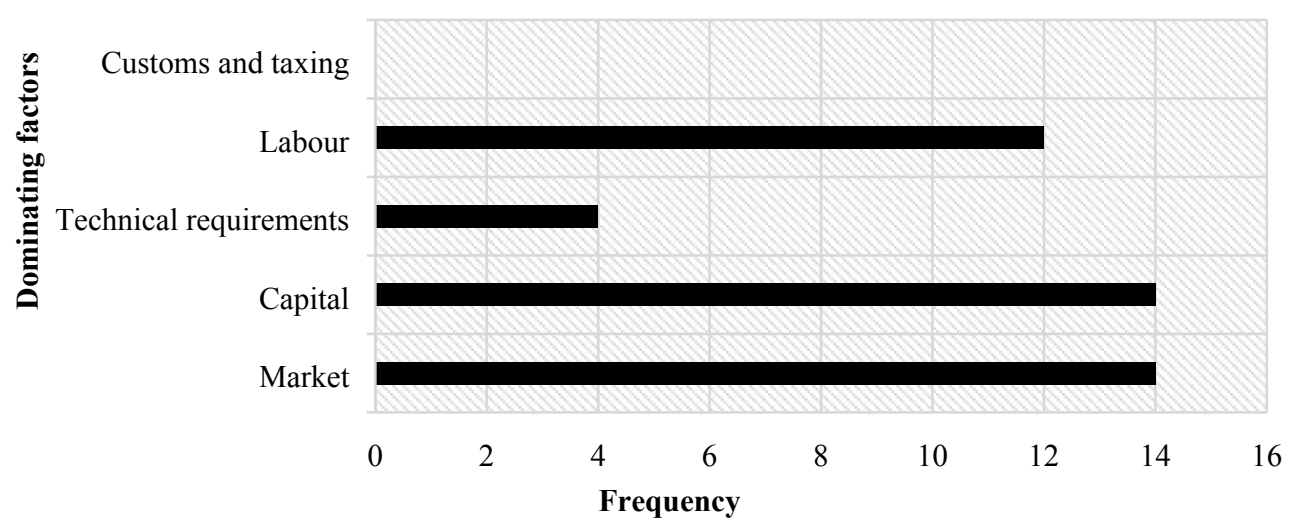

Figure 5. The dominating factors for mass production.

About the incentives in the Tanzanian context, the responses were into two groups. The first group was for the "potential investors or entrepreneurs into garment production" (Figure 6), and the second group was for the other organisations and enterprises (Figure 7). The majority of this list (Figure 6) were collected from the Textile Development Unit (TDU). Cotton is a dominating factor amongst textile students as an advantage. It is essential to point out that garment production may be performed on an import-processing-export basis that would 
not require the presence of cotton in Tanzania, but that would require the other mentioned factors. Here, labour availability is the second with the highest scores, although the disparity from cotton indicates how unpopular it was.

Furthermore, the group in question (Figure 7) is already part of the garment production labour forces. They are aware of the presence of sufficient labourers whenever they are needed. Only the larger-scale garment producers mentioned trade agreements because of their production levels. Cotton availability factor only featured slightly in comparison to Figure 6 due to the mainstream use of non-cotton fabrics by these garment makers. Market access, ports and political stability factors would play into a larger production scale which exports. Since many producers in this group do not operate at a high level, those factors thus were not in their prioritised factors.

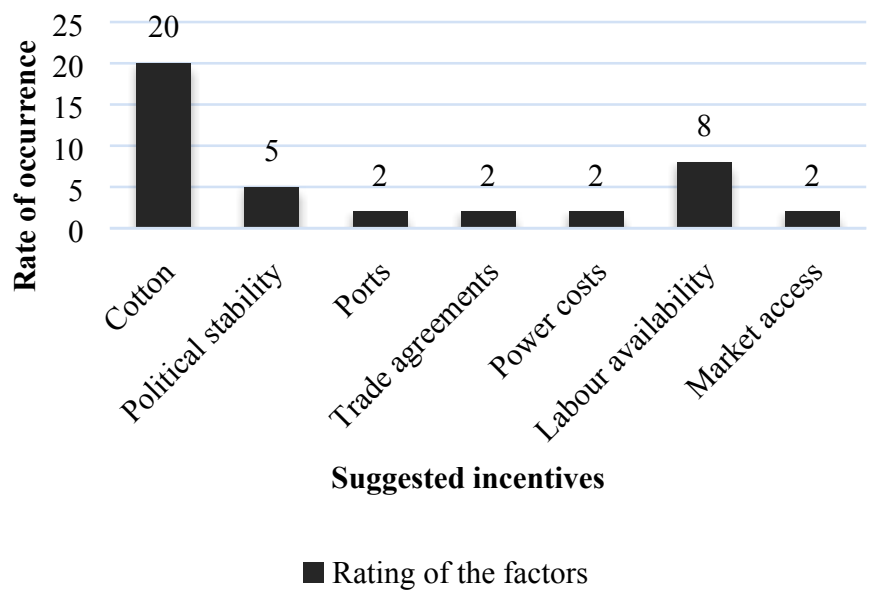

Figure 6. Suggested incentives in the garment production industry from potential investors.

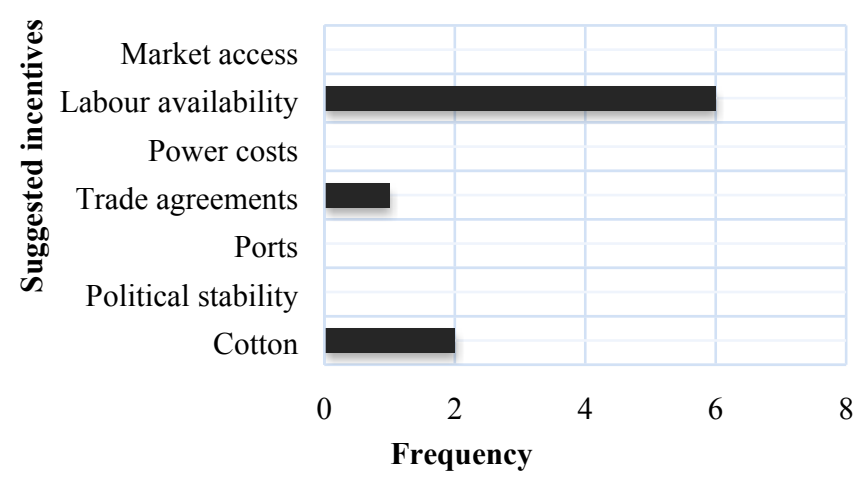

Figure 7. Suggested incentives in the garment production industry from experienced personnel. 
Moreover, the study explored other reasons for several setbacks in their garment production industries (Figure 8). The participants were the SMEs. Much expertise in manufacturing garments, particularly amongst the unskilled workforce, is informal and gained with practice. This points to the spike in Figure 8, indicating a need for more trained labourers in the production process. Access to funding also is amongst the highlighted aspects due to the machinery and rent of spaces costs to accommodate a large production line. Funding is also an issue for manufacturers looking to scale up their operations. Tanzania market is now importing cheaper garments, both new and used (famously known as Mitumba). This challenges producers who manufacture items for domestic consumption as the market becomes saturated with the imported apparels for lesser prices. Figure 8 also shows slow payments $(25 \%)$ as a challenge to producers processing large scale orders from domestic clients as the payment cycle takes longer than anticipated. The reliable electric power supply is a challenging subject. Although the power supply factor was mentioned, the problem is slowly diminishing. In contrast to this, Tanzania enjoys low current power charges (Figure 9).

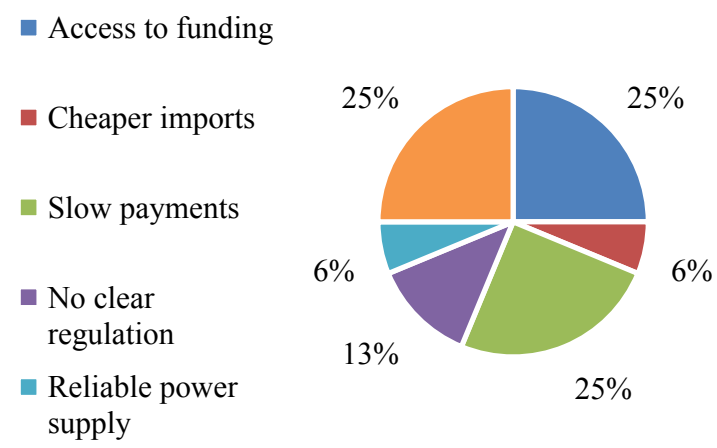

Figure 8. Setbacks experienced in the garment production industry.

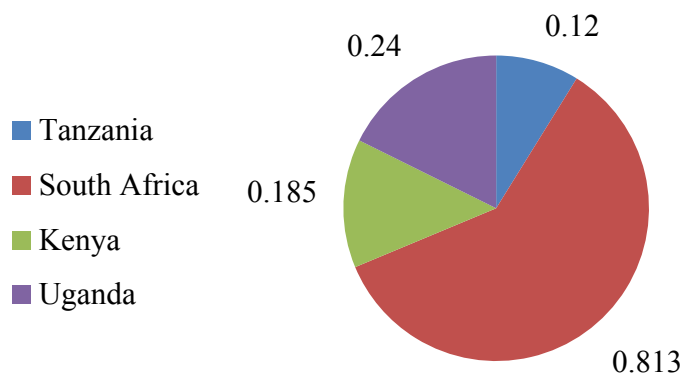

Figure 9. Comparison of a kilowatt-hour $(\mathrm{kWh})$ charges between the selected SSA countries and Tanzania (Mtunga, 2016). 
The results also show that the funding and training were common criteria for developing advancing production operations for all producers. When respondents were asked on terms with which they were much familiar regarding garment production, lookbooks featured with garment makers by $64 \%$. The lookbooks are used as a visual aid for the client to explain what they would like as design features on their garments. This is common from custom made tailors to larger manufacturers, and thus makes the familiarity of it.

Then, the study found that AGOA agreement is not popular amongst tailors, although its terms apply to garment makers on all levels. For the SMEs, only $18 \%$ of the participants knew AGOA. All large manufacturers knew AGOA by 100\%. AGOA is common amongst larger capacity manufacturers because those manufacturers are more inclined to take advantage of its provisions. Likewise, operation bulletins and standard apparel minutes are industrial level terms. These terms are uncommon at local or semi-professional production levels or without part of the formalised training in assembly line management. Only 9\% of the SMEs were aware of the standard operation time, i.e. Standard Minutes Value.

If mass production is to be achieved, then this would widen up for mass customisation, which should be viewed under the five fundamental methods for the standard products. These include: the creation of the customisable products, provide quick response, provide a point of delivery customisation, customise services around standard products, and modularising the components (Duray, 2002). Improvement of the sector needs great transformations. There are studies, (e.g. Salm et al., 2011; Kim, 2012), which show the way advancement in computer software and hardware technologies have digitalised many sectors including the T\&A sector in some countries. Thus, efficient technology can scale up outputs with a quick response to customers' orders, even mass customisation (Taifa and Desai, 2017; Taifa et al., 2019; Taifa and Vhora, 2019).

\section{Key requirements/toolkit}

\subsection{Introduction}

This section focuses on the crucial requirements one would need to know to set up and operate a GMP unit. The section acts as a toolkit for any individual(s) who needs to be aware of the complexities involved in establishing a production system as required. The toolkit has four parts: people or personnel, machines, operational knowledge and materials (Figure 10). This means people possess knowledge which is essential to operate machines. Then, machines assist 
in processing raw materials, e.g. (cotton, yarn, fabric, sewing thread, trims and accessories, etc.). However, investors mostly would prefer to prioritise the machines first.

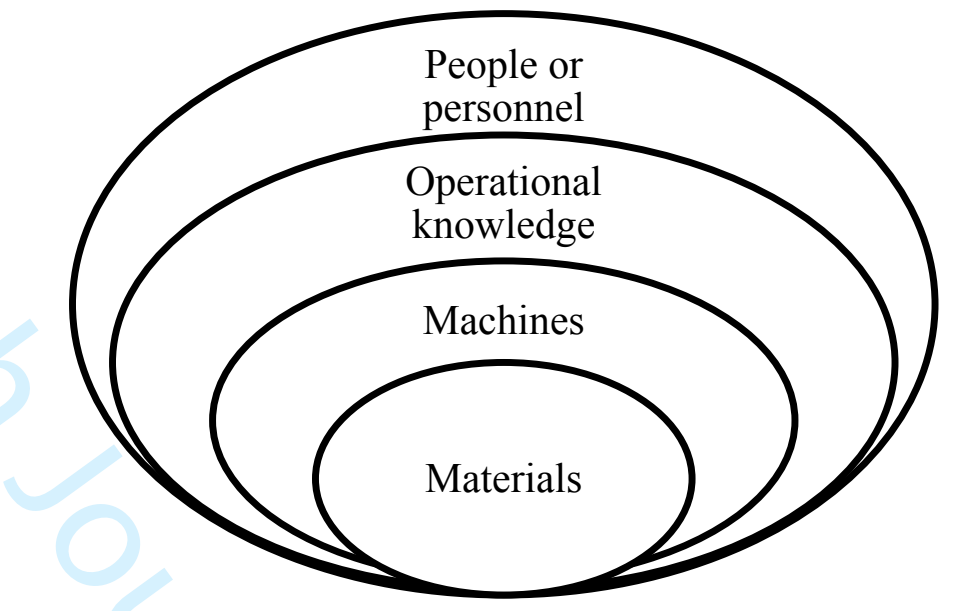

Figure 10. List of toolkit's components.

\subsection{Personnel}

The following are the roles involved in the direct production activities of a garment production unit. The study found institutions currently offering the certified training to produce experts in the roles such as designers, assistant designers, patternmakers, sample cutters, sample makers, production, pattern grader, marker maker, cutters and production sewers. The leading institutions offering the appropriate courses include the University of Dar es Salaam (UDSM) and the Vocational Education Training Authority (VETA). UDSM offers Bachelor of Science (B.Sc.) in Textile Design and Technology (4 years), B.Sc. in Textile Engineering (4 years) and Bachelor of Art in Art and Design (3 years). VETA offers courses related to design, sewing and cloth technology level I and II, textile surface finishing, garment construction, pattern drafting and sewing machine maintenance.

\subsection{Machines}

Mass production requires multiple machines. Prioritisation of the machine mix required (Table 2) depends on the type and quantities to be manufactured. For example, there is a need for installing more "over-edge" and "flatlock machines" if the factory produces knitted garments. However, for the production of woven products, there are many requirements for many lock stitch machines (Sarkar, 2012). It is essential to plan for an appropriate machine ratio when setting a new firm to avoid unnecessary delay, which can extend lead times and affect quick response to customers' orders. One should not only focus on selecting the correct categories of machines but also it is essential to have an appropriate number of the required machines to operate the new factory as well as adequately compete with other garment producers. Failure 
to balance the two can cause the problem to either side. If an investor could think of purchasing only the required machines at the initial stage, such a decision could lead to excellent control of the required initial capital investment. Machine mix processes are not an easy task. However, the following can be performed in getting an initial machine mix for a new factory (Figure 11).

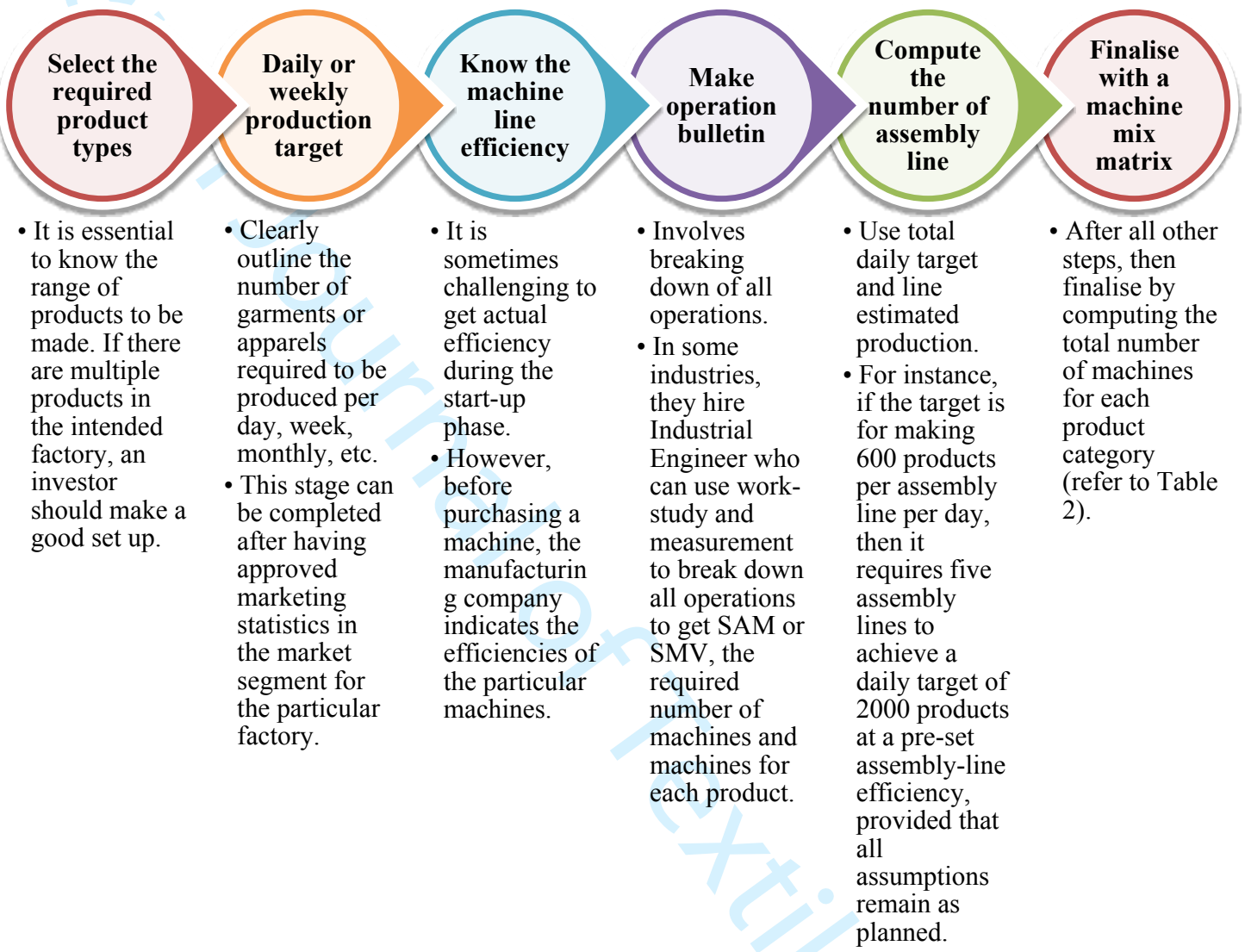

Figure 11. List of some procedures to set an initial machine mix for a new factory.

[Insert Table 2]

\subsection{Materials}

All garment industries require raw materials (RMs) as the major input to manufacture apparel. Industries may require either processed, unprocessed or both processed and unprocessed materials depending on the nature of the industry and products being produced. Examples of the RMs include cotton, yarn, dyes, fabric, sewing thread, trims and accessories, etc. Some mass production units can process most of the RMs from their manufacturing premises as their factories comprise spinning, weaving, chemical and knitting workstations among others. Such production units need both processed and unprocessed raw materials. Other industries may only need CMT facilities. CMT includes cutting the fabric, making (sewing) garments and 
trimming, together with the cleaning processes and the packaging processes of the finished apparel. For such industries, they mostly require processed materials.

\subsection{Operational knowledge requirements}

Operational knowledge requirements are a series of documents and operational procedures which should be known in the production process (Table 3). Such requirements are pertinent to successfully managing the garment production line.

[Insert Table 3]

\section{Specific considerations for Tanzania}

\subsection{Trade agreements (trade pact)}

These comprise widespread taxes, trade treaty and tariff. Trade pact happens when there are at least two countries acquiesces on conditions that assist in trading amongst them.

\section{(a) African Growth and Opportunity Act (AGOA)}

AGOA is a "non-reciprocal and unilateral preference program that provides duty-free, quotafree access to the U.S. market for qualifying goods from eligible SSA countries" (USAID, 2016, p.10). It is the USA Trade Act, ratified on 18/05/2000 as a "Public Law 106" of the two hundredth Congress. In 2015, AGOA was extended up to 2025. By 2018, AGOA had 40 eligible countries from Africa (Schneidman and Signé, 2018). Tanzania, as one of the SSA countries, should reap AGOA's benefits. Up to 2016, there were only two firms that benefited from AGOA - Tooku in Dar es Salaam and Mazava located in Morogoro. The two firms have a total of 4000 workers. This leaves an ample room for other firms together with those being established on an annual basis (USAID, 2016). AGOA provides noticeable motivations for SSA countries to put their efforts in opening up their economies and create free markets (Schneidman and Lewis, 2012). Some requirements for eligible countries under AGOA include aspects of human rights, the rule of law and respect for core labour standards. The presence of AGOA is thus one of the substantial incentives to be utilised by the garment producers in Tanzania, specifically for those intended to establish mass-production factories.

\section{(b) Everything but Arms (EBA)}

EBA is among advantageous trade preferences for Tanzania (USAID, 2014; TDU, 2018). Under the EBA initiative, all tariffs are reduced to zero for all imported products from the "Least Developed Countries (LDCs)" with exceptions to armaments and arms (Cernat et al., 2004). By 2018, EBA had 49 beneficiaries, including Tanzania. This thus serves as an excellent 
opportunity for mass production in Tanzania. The garment producers can export their products under the quota-free and duty-free aspect in the EU. In addition to EBA and AGOA, Tanzania can utilise other trade preferences, including the EAC regional markets and the SADC for reaching the Southern Africa market.

\subsection{Other reasons for investing in Tanzania}

a) The potentials offered by the Tanzania T\&A sub-sector is substantial and wide-ranging. Tanzania is one of Africa's major producers of high-quality cotton. The average crop yield of seed cotton for the past three years is 275,700 tonnes.

b) Tanzania's attractive investment climate stands out in the region and beyond. Tanzania has a dedicated T\&A support unit - TDU based on the Ministry of Industry Trade and Investment (MITI), competitive, low wages and an impressive range of investment incentives (Table 4). MITI has the mission of facilitating the development of sustainable industry and trade sectors by enhancing "environment" and "improved services". There is also the "Textile and Garment Manufacturers Association of Tanzania (TEGAMAT)", Gatsby Africa, the National Development Corporation (NDC), the Tanzania Investment Centre (TIC), the African Cotton and Textile Industries Federation, EPZA, etc.

c) The people of Tanzania buried their cultural, ethnic, religious and political differences, and they enjoy peace ever since attaining independence over 58 years ago. A common language, Swahili unite the people. Tanzania is indeed one of the most stable and peaceful business environments in the developing world.

d) The country, located on the Indian Ocean, has unparalleled access in the region to export markets via three major seaports and land borders with eight adjacent markets.

e) As part of Tanzania's strategy to achieve middle-income country status by 2025 , T\&A manufacturing is part of the prioritised sub-sectors. The government provides full support and necessary incentives to influence the establishment of garment industries growth (URT, 2017). There is also a high demand for garments and knitted fabrics in Tanzania. Other factors include low-cost labour and reliable energy supply, etc.

Figure 12 summarises the key factors for investing in Tanzania as provided by TDU participants together with TDU (2018). These factors help for establishing mass garment production units both for domestic and exportation purposes. Similarly, Table 4 depicts an evaluation of factors which also helps to decide whether to invest in Tanzania or elsewhere. Tanzania, however, should shorten the time to clear customs. As of 2015 statistics, an investor 
had to wait for 44 days to clear customs issues. Based on the DIP, the time has been shortened to invite more investors. Additionally, the labour skills factor is rated 'low" compared to Kenya. The country needs to strengthen existing institutions - UDSM and VETA to have professional and competent workforces.

\section{[Insert Table 4]}

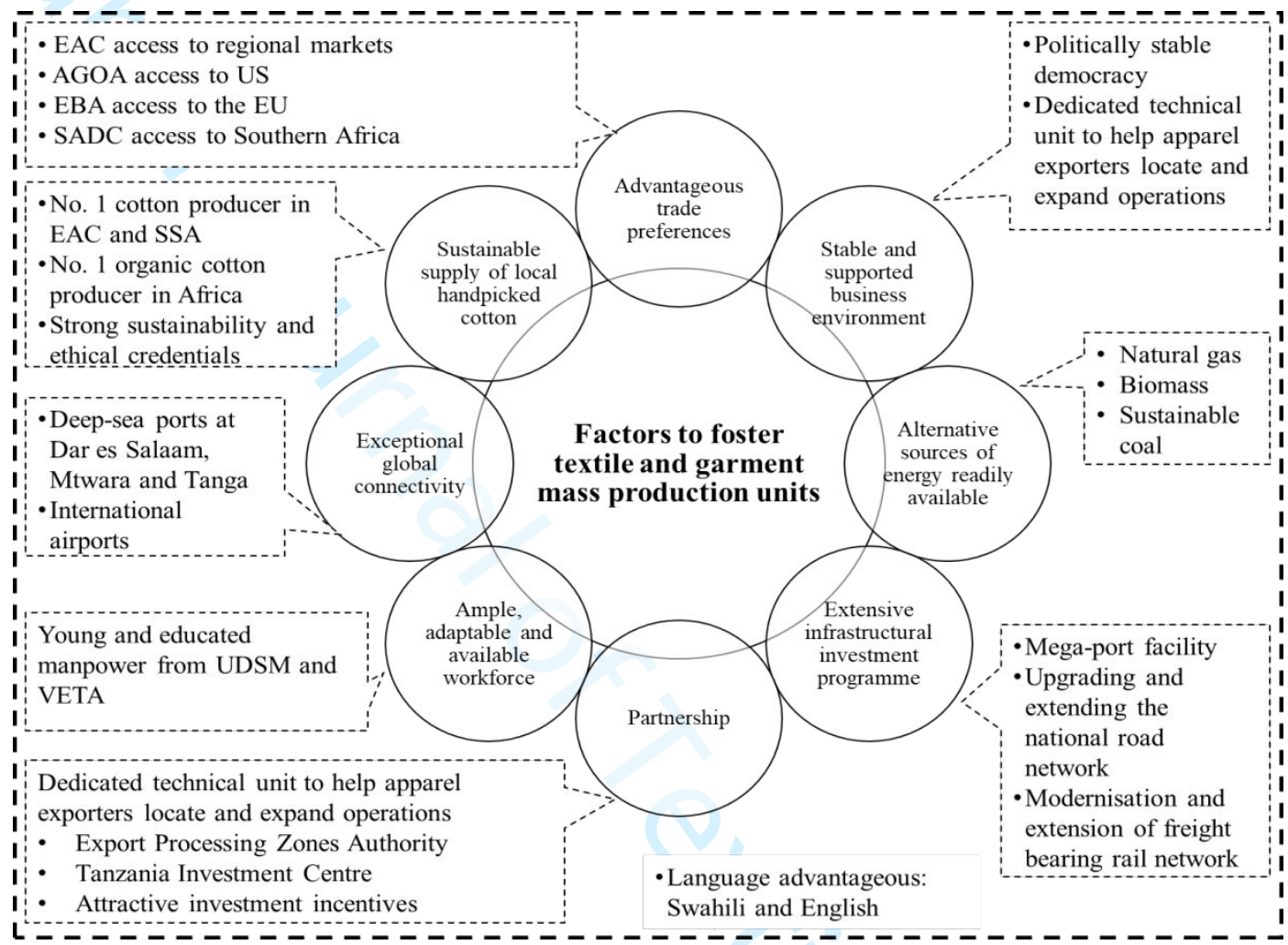

Figure 12. Potential factors for establishing mass-producing textile and garment units in Tanzania.

Establishing mass production factories requires sufficient raw materials. Such materials include cotton. Tanzania is the leading cotton producer within the EAC. Due to the presence of few garment factories, it is not surprising that farmers are paid less because of the unbalance between demand and supply of cotton. Coulson $(2016$, p.54) stated that "it is surprising that Tanzanian farmers continue to grow cotton." Then, Coulson (2016) clarifies why farmers continue their farming activities. The reasons are that "the crop is well adapted for the semiarid conditions around Lake Victoria, and because they need money. Other options for the use of their labour time are also risky, and they choose to cultivate a variety of crops, of which cotton is one." If there were several large garment manufacturing factories, the demand of the produced cotton in Tanzania would increase, thus increasing the producers' income. 


\section{Practical contributions}

This research provides insights for the available opportunities in the textiles and garment industry in Tanzania. It is expected that the results will enlighten and impart a significant understanding of the essential elements of the mass production units. Both the government, through its Ministry, investors, workers, potential investors, allied organisations, etc. can benefit from this study. This study has more managerial implications rather than the theoretical implications which could benefit the overall relevant fields of academia. Generally, the study's significance arises from the particular era that is characterised by the insistence on industrialisation by the government, the availability of resources and the academic potential offered by the textile courses at UDSM and VETA. The identified information and factors lead to the jump in textile-based industries. As such, up to date information resources concerning an aspect such as garment production that is relevant to Tanzania is an appropriate tool for both individuals and corporations intending to establish a GMP. Past few years, there has been an upsurge in manufacturing costs in China. For the last two decades, China has been leading and perhaps still leads other countries in exporting the T\&A products into the Western markets. However, there is an observed shift that now substantial volumes of the T\&A orders are sourced from other countries, including India, Bangladesh, Cambodia and Vietnam. Nevertheless, Salm's et al. (2011) study shows that buyers are also slightly shifting and are perceiving that Africa is the next opportunity for investing and sourcing for the potential raw materials and ready-made products, especially considering preferential trade access by some of the SSA countries. This ma'kes Tanzania as one of the African countries set to strengthen in her domestic industrial sector by utilising mass production units throughout the country.

\section{Concluding remarks}

\subsection{Conclusion}

This study deployed a qualitative approach by involving a total of 72 participants. Cronbach's Alpha tested an "internal consistency" of the used questionnaires. The Cronbach's Alpha $(\alpha)$ value was 0.909 ; i.e. this is high internal consistency since $\alpha \geq 0.9$. Through qualitative analysis, some of the essential factors in establishing a GMP unit were found to be market, capital and labour. Other reasons to scale up the SMEs include the availability of the raw materials, factors include low-cost labour, excellent government support and reliable energy supply among others. The study also developed a toolkit which includes four parts - people or personnel, machines, operational knowledge and materials. 
The study also shows the available trade advantages from EBA, AGOA, SSA, EAC and SADC coalitions. The Tanzanian context has been selected not only for the case of it being the locality of the research but also as a result of its emergence as a potentially ripe location for conducting garment production operations. The garment industry also presents incredible potential employment and overall economic impact on the country. Garment making on small scales has existed for a long enough time to make the sewing culture a mainstream phenomenon today. The leap towards garment mass production should not look like an impossibility. This study put thus forward sufficient evaluations on existing producers, required information, key requirements and consequently forge the way forward. This would probably enable the country to cater to her population and successfully help Tanzania become a sourcing destination for apparels, particularly with the added advantage of trade agreements, abundant labours and other resources.

Tanzania as a country, requires significant investment, well-planned strategies, a good industrialisation plan, empowered workforces through the existing institutions, international collaborations with foreign investors, implementable policies among others to lead other SSA countries in executing profitable garment mass production. It is also useful to benchmark from the well-stabilised countries and industries in this sector. The target should be to satisfy both the domestic and international markets, especially by utilising AGOA and EBA opportunities.

\subsection{Recommendations and further research}

The research findings suggest several actions for continued efforts that needed to make more accessible mass production in Tanzania.

(a) To conduct market research (survey) on the garments demand in Tanzania. The study results indicate that there is a need for the survey of Tanzania garment market. Its results would also constitute pertinent information to potential investors and current manufacturers. A distinction to be made here may be the determination of the market regarding domestic apparel needs for everyday use and industrial or institutional garment needs, e.g. uniforms or work clothing.

(b) Increase offered training to the university and vocational students on the complexities of garment production. This would increase familiarity with concepts around the process management of the assembly line. This would also facilitate the step by step, practically regarding the garment production line for domestic and export purposes. 
(c) The further formalisation of the garment industry to promote regulation and fair trade amongst semi-professional garment producers is required. Such formalisation processes can enable better-tendering processes for garment manufacturers and more organised manufacturing systems. This would enable several semi-professional producers to advance their operation to more formal production and increase their capacities.

(d) To create an internal body of standards for garment manufacturing and stricter controls on standards. A standardisation part of the domestic garment industry can work well with the formalisation process to maintain a certain level of quality. It can correspondingly create some guidelines for the manufacturers. Proper standardisation can similarly help the exportation of the manufactured garments and thus increase the market range.

\section{References}

Baset, M.A. and Rahman, M. (2016), "Application of industrial engineering in garments industry for increasing productivity of sewing line", International Journal of Current Engineering and Technology, Vol. 6 No. 3, pp. 1038-1041.

Berry, B., Howcroft, J., Ward, J., Ford, R., Gong, H., Kennon, R., Towers, N., et al. (2007), The cotton and textiles sector in Tanzania: Issues and opportunities, Tanzania Gatsby Trust, Dar es Salaam, Tanzania.

Bertola, P. and Teunissen, J. (2018), "Fashion 4.0. Innovating fashion industry through digital transformation", Research Journal of Textile and Apparel, Vol. 22 No. 4, pp. 352-369.

Bheda, R., Narag, A.S. and Singla, M.L. (2003), “Apparel manufacturing: a strategy for productivity improvement”, Journal of Fashion Marketing and Management, Vol. 7 No. 1, pp. 12-22.

Bolarinwa, O. (2015), "Principles and methods of validity and reliability testing of questionnaires used in social and health science researches", Nigerian Postgraduate Medical Journal, Vol. 22 No. 4, pp. 195-201.

Calabrese, L., Balchin, N. and Mendez-Parra, M. (2017), The phase-out of second-hand clothing imports: What impact for Tanzania?, No. 82175, Munich Personal RePEc Archive (MPRA).

Cernat, L., Laird, S., Monge-roffarello, L. and Turrini, A. (2004), “The EU Everything But Arms initiative and the LDCs", in Guha-Khasnobis, B. (Ed.), The WTO, Developing 
Countries and the Doha Development Agenda. Studies in Development Economics and Policy, Palgrave Macmillan, London, pp. 219-220.

Chen, C.-H. and Shih, H.-T. (2004), "The impact of WTO accession on the Chinese garment industry”, Journal of Fashion Marketing and Management, Vol. 8 No. 2, pp. 221-229.

Coulson, A. (2016), "Cotton and textiles industries in Tanzania: the failures of liberalisation", Review of African Political Economy, Vol. 43, pp. 41-59.

Duguay, C.R., Landry, S. and Pasin, F. (1997), "From mass production to flexible/agile production", International Journal of Operations \& Production Management, Vol. 17 No. 12, pp. 1183-1195.

Duray, R. (2002), “Mass customization origins: mass or custom manufacturing?", International Journal of Operations \& Production Management, Vol. 22 No. 3, pp. 314328.

Equity Bank. (2016), The Kenyan Textile and Fashion Industry, Equity Bank, Hivos East Africa Office, Nairobi, Kenya.

Faber, G. and Orbie, J. (2009), "Everything but arms: Much more than appears at first sight", Journal of Common Market Studies, Vol. 47 No. 4, pp. 767-787.

Fukunishi, T. and Ramiarison, H.A. (2012), Madagascar's Garment Industry: Success of Africa's Garment Exports?, Dynamics of the Garment Industry in Low-Income Countries: Experience of Asia and Africa (Interim Report), Chousakenkyu Houkokusho, IDEJETRO, Japan.

Fukunishi, T. and Yamagata, T. (2013), Slow and steady wins the race: How the garment industry leads industrialization in low-income countries, Institute of Developing Economies: Japan External Trade Organization, Japan.

Gabagambi, D.M. (2013), "Post-liberalisation paradox in textile industry: a comparative study of Vietnam and Tanzania”, International Journal of Business and Social Science, Vol. 4 No. 8, pp. 191-201.

Gockeln, L. (2014), Fashion industry analysis from the perspective of business model dynamics, University of Twente, Enschede, The Netherlands.

Harder, F. (2004), Fashion for profit: A professional's complete guide to designing, 
manufacturing, \& marketing a successful line, edited by Gross, S., 9th ed., Harder Publications, USA.

ITC. (2016), United Republic of Tanzania cotton-to-clothing strategy 2016-2020, The International Trade Centre (ITC), Geneva, Switzerland.

Jones, J.V.S. (1983), Resources and Industry in Tanzania: Use, Misuse and Abuse, Tanzania Publishing House, Dar es Salaam.

Kim, E. and Johnson, K.K.P. (2009), "Forecasting the US fashion industry with industry professionals - part 1: Materials and design”, Journal of Fashion Marketing and Management, Vol. 13 No. 2, pp. 256-267.

Kim, S. (2012), "Mass production of digital garments using multi-option data structure", International Journal of Clothing Science and Technology, Vol. 24 No. 2, pp. 89-101.

Kinabo, O.D. (2004), "The textile industry and the mitumba market in Tanzania", TanzaniaNetwork.de Conference on Textile Market and Textile Industry in Rural and Urban Areas in Tanzania on 23rd October 2004, Potsdam, Germany.

Kusnezov, X. (2012), Custom Made Fashion, Bachelor's thesis, HAMK Häme University of Applied Sciences, Hämeenlinna, Finland.

Mirzamakhmudov, R., Wei, L. and Akankwasa, N.T. (2013), "Study of supply chain management of apparel order process: a case study of Uzbekistan apparel industry", Journal of Logistics \& Supply Chain Management, Vol. 1 No. 8, pp. 380-394.

Morris, M. and Staritz, C. (2014), “Industrialization trajectories in Madagascar's export apparel industry: ownership, embeddedness, markets, and upgrading", World Development, Vol. 56, pp. 243-257.

Mtunga, M. (2016), Cotton, textile and apparel sector investment profile, International Trade Centre (ITC), Geneva, Switzerland.

Nhung, T.T.B. and Thuy, T.T.P. (2018), "Vietnam's textile and garment industry: an overview", Journal Business \& IT, Vol. VIII No. 2, pp. 45-53.

Nzumile, J.M. and Taifa, I.W.R. (2019), “Assessing the awareness of local consumer's product producers towards packaging standards in Tanzania", International Journal of Research in Industrial Engineering, Vol. 8 No. 1, pp. 40-52. 
Omolo, J.O. (2006), The textile and clothing industry in Kenya, edited by Jauch, H. and TraubMerz, R.The Future of the Textile and Clothing Industry in Sub-Saharan Africa, Bonn: Friedrich-Ebert-Stiftung.

Rita, A.A. and Mahamud, S. (2016), "Effectiveness of technical packages for the apparel production process in the global apparel industry", IOSR Journal of Business and Management, Vol. 18 No. 9, pp. 47-51.

Rweyemamu, J. (1973), Underdevelopment and industrialization in Tanzania: A study of perverse capitalist industrial development, Oxford University Press, Nairobi.

Salm, A., Dinsdale, P., MacDonald, D., Martelli, C., Hill, K. and Kabissa, J. (2011), Tanzania textiles and garment development strategy, Ministry of Industry and Trade, Dar es Salaam, United Republic of Tanzania.

Sarkar, P. (2012), "How to determine machines requirement for a new factory?", Online Clothing Study (OCS), available at: https://www.onlineclothingstudy.com/2012/08/howto-determine-machines-requirement.html (accessed 25 January 2019).

Schneidman, W. and Lewis, Z.A. (2012), The African Growth and Opportunity Act: Looking Back, Looking Forward, The Brookings Africa Growth Initiative Brookings institution, Washington, USA.

Schneidman, W. and Signé, L. (2018), “The 2018 AGOA Forum: A turning point for USAfrica commercial relations?", available at: https://agoa.info/news/article/15463-the2018-agoa-forum-a-turning-point-for-us-africa-commercial-relations.html (accessed 26 January 2019).

Selladurai, R.S. (2004), "Mass customization in operations management: Oxymoron or reality?", Omega, Vol. 32 No. 4, pp. 295-300.

Sun, X. (2018), Second-Hand Clothing Imports and the Textile and Apparel Industry in Africa, North Carolina State University, Raleigh, USA.

Taifa, I.W. (2016), Integration of Quality Function Deployment (QFD) and Ergonomics Principles in Product Design Improvement. Case Study: Student Desk at Engineering College, Gujarat Technological University, Ahmedabad, Gujarat, India.

Taifa, I.W. and Desai, D.A. (2016), "Student-defined quality by Kano model: A case study of Engineering students in India”, International Journal for Quality Research, Vol. 10 No. 
3, pp. 569-582.

Taifa, I.W. and Desai, D.A. (2017), "User requirements customization and attractive quality creation for design improvement attributes", International Journal for Quality Research, Vol. 11 No. 1, pp. 131-148.

Taifa, I.W.R., Desai, D.A. and Bulsara, N.M. (2019), “The development of an ergonomically designed product through an integrated product team approach”, International Journal of Occupational Safety and Ergonomics, pp. 1-19.

Taifa, I.W.R., Hayes, S.G. and Stalker, I.D. (2019), “Towards a digital revolution in the UK apparel manufacturing: an Industry 4.0 perspective", 2nd International Conference on Sustainable Smart Manufacturing (S2M 2019), Manchester, UK.

Taifa, I.W.R. and Vhora, T.N. (2019), "Cycle time reduction for productivity improvement in the manufacturing industry", Journal of Industrial Engineering and Management Studies, Vol. 6 No. 2, pp. 147-164.

TDU. (2018), Sourcing and Investment Opportunities in Tanzania for Textile and Apparel Businesses, Textile Development Unit (TDU), Dar es Salaam, Tanzania.

URT. (2017), Simiyu Region Investment Guide, United Republic of Tanzania (URT), President's Office, Regional Administration and Local Government, Dar es Salaam.

USAID. (2014), Strengthening the Cotton, Textile and Apparel Value Chain in East Africa: An Assessment, United States Agency for International Development (USAID), USA.

USAID. (2016), National AGOA Strategy for The United Republic of Tanzania, The United States Agency for International Development, Bethesda, Maryland, USA. 
Table 1. Summary of the participants.

\begin{tabular}{lccc}
\hline \multirow{2}{*}{ Participants } & \multicolumn{2}{c}{ Number of participants } & \multirow{2}{*}{ Total } \\
\cline { 2 - 3 } & Male & Female & \\
\hline Potential investors or entrepreneurs in garment production & 30 & 14 & 44 \\
Semi-professional mass garment producers & 10 & 7 & 17 \\
Inputs from relevant allied organisations & 1 & 1 & 2 \\
Tailoring mart owners and workers & 6 & 3 & 9 \\
Total & 47 & 25 & 72 \\
\hline
\end{tabular}

Table 2. Example of a Machine Mix Matrix.

\begin{tabular}{lllllll}
\hline & Type of machines & \multicolumn{3}{c}{ Product-wise number of required machines } & \\
\cline { 2 - 5 } S/N & Sewing operations & $\begin{array}{l}\text { Bedsheet } \\
(3 \mathrm{AL})\end{array}$ & $\begin{array}{l}\text { School shirts } \\
(6 \mathrm{AL})\end{array}$ & $\begin{array}{l}\text { T-shirt } \\
(8 \mathrm{AL})\end{array}$ & $\begin{array}{l}\text { Kitenge and } \\
\text { Khanga } \\
(10 \mathrm{AL})\end{array}$ & \multirow{2}{*}{ Total } \\
\hline 1. & Machine A & $\mathrm{N} 1$ & $\mathrm{~N} 2$ & $\mathrm{~N} 3$ & $\mathrm{~N} 4$ & $\sum \mathrm{N}(1,2,3,4)$ \\
2. & Machine B & $\mathrm{N} 5$ & $\mathrm{~N} 6$ & $\mathrm{~N} 7$ & $\mathrm{~N} 8$ & $\sum \mathrm{N}(5,6,7,8)$ \\
3 & Machine C & $\mathrm{N} 9$ & $\mathrm{~N} 10$ & $\mathrm{~N} 11$ & $\mathrm{~N} 12$ & $\sum \mathrm{N}(9,10,11,12)$ \\
Total number of the & $\sum \mathrm{N}$ & $\sum \mathrm{N}(2,6,10)$ & $\sum \mathrm{N}$ & $\sum \mathrm{N}(4,8,12)$ & $\sum($ machines $)$ \\
required machines & $(1,5,9)$ & & $(3,7,11)$ & & \\
\hline
\end{tabular}

Note(s): N: a specific number of machines; AL: assembly lines.

Table 3. Operational knowledge requirements.

\begin{tabular}{|c|c|c|c|}
\hline $\mathrm{S} / \mathrm{N}$ & $\begin{array}{l}\text { Required } \\
\text { operational } \\
\text { documents }\end{array}$ & Description & Source \\
\hline 1 & $\begin{array}{l}\text { An operation } \\
\text { bulletin }\end{array}$ & $\begin{array}{l}\text { It is a process of breaking down all tasks to get total jobs } \\
\text { required to complete one garment. Industrial Engineers are } \\
\text { equipped with such knowledge of making operational bulletin. }\end{array}$ & $\begin{array}{l}\text { Baset and } \\
\text { Rahman (2016) }\end{array}$ \\
\hline 2 & $\begin{array}{l}\text { Spec sheets } \\
\text { (specification } \\
\text { sheet) and quotes }\end{array}$ & $\begin{array}{l}\text { It is the first item to be available to any garment manufacturer. } \\
\text { The sheet details information regarding product description, } \\
\text { product code, required finishing, cuttable width, fabrics, } \\
\text { printing techniques, measurements, important images or } \\
\text { diagrams, zipper and button, costing information, woven } \\
\text { labels, lining details, swing tags, etc. The spec sheets should } \\
\text { give enough information as much as possible. From spec } \\
\text { sheets, it is possible to get production quotes. }\end{array}$ & $\begin{array}{l}\text { Kim and } \\
\text { Johnson (2009) }\end{array}$ \\
\hline 3 & Line sheets & $\begin{array}{l}\text { It provides the necessary details of potential customers. A line } \\
\text { sheet contains details related to styles, style numbers, fabric } \\
\text { information and colour, contact details of the company or } \\
\text { factory, prices, minimum orders, order cut off dates, possible } \\
\text { delivery dates, etc. By having a line sheet, it is possible to see } \\
\text { the garment sizes, size ranges, etc. easily. In most cases, line } \\
\text { sheets are used for the wholesale business of the garments. }\end{array}$ & Harder (2004) \\
\hline 4 & $\begin{array}{l}\text { Tech packs } \\
\text { (Technical } \\
\text { package) }\end{array}$ & $\begin{array}{l}\text { It is a detailed intensive sheet which is used by fashion } \\
\text { designers to communicate with their manufacturers regarding } \\
\text { all essential elements required to make garments. It details } \\
\text { technical drawings, style numbers, quality control issues, } \\
\text { reference materials, a pattern, embroidery details, packaging, } \\
\text { testing method details, etc. }\end{array}$ & $\begin{array}{l}\text { Rita and } \\
\text { Mahamud } \\
(2016)\end{array}$ \\
\hline
\end{tabular}




\begin{tabular}{llll}
\hline 5 Lookbooks & $\begin{array}{l}\text { A lookbook can be explained as a gathering of numerous } \\
\text { photographs compiled as a way of showing up a brand, } \\
\text { retailer, stylist or style and/or clothing line. It should be added } \\
\text { to the company's website. }\end{array}$ & $\begin{array}{l}\text { Kusnezov, } \\
(2012) ;\end{array}$ \\
& Gockeln (2014)
\end{tabular}

Table 4. Evaluation of the competitive factors and costs between the URT together with the few selected countries.

\begin{tabular}{|c|c|c|c|c|c|c|}
\hline Projected values & Tanzania & Vietnam & China & Kenya & India & Ethiopia \\
\hline $\begin{array}{l}\text { T\&C export value (USD millions, } \\
\text { 2013) }\end{array}$ & 248 & 21534 & 273959 & 377 & 40192 & 94 \\
\hline Labour skills & Low & High & $\begin{array}{l}\text { Very } \\
\text { high }\end{array}$ & $\begin{array}{l}\text { Low- } \\
\text { medium }\end{array}$ & High & Low \\
\hline $\begin{array}{l}\text { Time for customs clearance, inputs and } \\
\text { exports (days) }\end{array}$ & 44 & 15 & 17 & 31 & 12 & 37 \\
\hline Labour cost (USD/month) & 70 & $180-200$ & 550 & $110-150$ & 175 & $50-60$ \\
\hline $\begin{array}{l}\text { Production of Cotton (thousands of } \\
480 \text {-pound bales) }\end{array}$ & 375 & 17 & 30000 & 32 & 30000 & 175 \\
\hline $\begin{array}{l}\text { Electricity cost (USD/kWh) - } \\
\text { estimated average }\end{array}$ & 11 & 8 & $9-15$ & $9-12$ & $7-12$ & $2-5$ \\
\hline $\begin{array}{l}\text { Lending rates (Annual Percentage } \\
\text { Rates - estimated) }\end{array}$ & 19 & $6-7$ & 7 & $14-18$ & $7-13$ & 8.5 \\
\hline Cost of construction (USD $/ \mathrm{ft}^{2}$ ) & 43 & $20-25$ & $15-20$ & 21 & $18-20$ & 40 \\
\hline $\begin{array}{l}\text { Annual sales lost to electrical outages } \\
\text { in percentage }\end{array}$ & 5.5 & 1.1 & 0.1 & 5.6 & 2.0 & 2.6 \\
\hline
\end{tabular}

Note(s): $\mathrm{ft}^{2}=$ square Foot; $\mathrm{T} \& \mathrm{C}=$ Textile $\&$ Clothing. Source: Doing Business Report and ITC calculations (2015) as cited by (ITC, 2016). 